\title{
INSTITUCIONES, ISLAM Y \\ DESARROLLO ECONÓMICO \\ EN PERSPECTIVA HISTÓRICA
}

La larga divergencia: la influencia de la ley islámica en el atraso de Oriente Medio, Timur Kuran, Granada, Universidad de Granada, 2017, 448 pp.

Juan Antonio Rubio Mondéjar*

$\mathrm{O}$ riente Medio es una región atrasada desde el punto de vista económico. Si se comparan el Índice de Desarrollo Humano, la esperanza de vida al nacer, la tasa de alfabetización de la población adulta y el PIB per cápita de los países de Oriente Medio y de los países que forman parte de la ocDE (excepto Turquía), no cabe otra conclusión. Con la comparación de estos indicadores de desarrollo comienza La gran divergencia, una obra que pretende explicar las causas del atraso de esa región con el auxilio de la teoría económica neoinstitucional.

Timur Kuran, economista y sociólogo de Duke University, se dio a conocer al popularizar el concepto de falsificación de preferencias (preference falsification) en el ámbito de las ciencias políticas y la sociología. A pesar de ese éxito académico, pronto desvió su investigación para analizar las razones del subdesarrollo de los países musulmanes (Kuran, 1997). Con la publicación en 2011 de The long divergence: How Islamic law held back the Middle East, el autor se consagró como uno de los mayores expertos en el desempeño económico del mundo islámico en el largo plazo. Kuran planteó la discusión en términos distintos a los de las posiciones más asentadas: por un lado, la de quienes defendían la incapacidad de las sociedades islámicas para adoptar las instituciones del capitalismo moderno, nacidas y desarrolladas en Occidente; y por otro lado, la de quienes argumentaban

\footnotetext{
* Doctor en Ciencias Económicas y Empresariales, profesor del Departamento de Teoría e Historia Económica, Universidad de Granada, Granada, España, [jarubio@ugr.es]. Fecha de recepción: 27-07-2017, fecha de aceptación: 04-09-2017. Sugerencia de citación: Rubio M., J. A. (2017). Instituciones, Islam y desarrollo económico en perspectiva histórica. Revista de Economía Institucional, 19(37), 339-342. DoI: https://doi.org/10.18601/01245996.v19n37.18
} 
que la causa de su limitado desempeño económico es el abandono de las instituciones propias de las sociedades islámicas.

En 2017, cuando se publica la versión en español de La gran divergencia, la discusión sigue sin resolverse. La situación de los países de Oriente Medio es, si cabe, más dramática que en 2011: en Siria, la guerra civil va camino del séptimo año; parte del territorio sirio e iraquí está bajo control del régimen fundamentalista de Daesh; el gobierno turco avanza por la senda del autoritarismo; la población desplazada por los conflictos bélicos atestigua la falta de solidaridad de los Estados europeos; el terrorismo integrista se extiende por el mundo... Al margen de la influencia decisiva de factores externos en esta lista de conflictos, se confrontan de nuevo las dos visiones: falta de flexibilidad para asumir las transformaciones que requiere el sistema capitalista o retorno a un pasado pretendidamente idílico regido por la ley islámica. El libro de Kuran muestra que se trata de una cuestión más compleja, que hunde sus raíces en un pasado lejano.

La gran divergencia no analiza la actualidad sino el periodo en el que, según su autor, se produjo el estancamiento de Oriente Medio con respecto a Europa Occidental. Un debate popular en historiografía económica es el de la separación de las trayectorias de Europa Occidental y de los países de Extremo Oriente, en especial de China e India, el cual se ha datado en los siglos XV y XVI, coincidiendo con la expansión comercial y la integración de América en el mercado global ${ }^{1}$. Para Kuran, Oriente Medio inició la divergencia mucho antes, hacia el año 1000. La fecha no es aleatoria: el análisis institucional comparado -el método en el que basa su argumentación-, sugiere que las mismas instituciones que sustentaron la expansión de los primeros siglos del Islam serían la causa de su estancamiento posterior. Las ventajas estáticas iniciales de esas instituciones se convertirían en desventajas dinámicas, al dificultar o impedir su evolución o transformación para adaptarse a las nuevas necesidades de la economía. Kuran introduce así, al mismo tiempo, el problema de la "dependencia de la trayectoria”, un concepto clave de la nueva economía institucional, que supone que una vez establecido un marco institucional se erigen fuertes resistencias que imposibilitan su modificación.

El planteamiento del profesor Kuran, que huye de la "falacia de la prioridad absoluta”, es decir, de las explicaciones monocausales, encaja plenamente con la teoría de las instituciones desarrollada por el primer North (North y Thomas, 1973; North 1990): el desarrollo económico

\footnotetext{
${ }^{1}$ Para una excelente revisión del debate sobre la gran divergencia, que sitúa la obra de Kuran en perspectiva comparada, ver López (2016).
} 
depende de la capacidad de crear instituciones que permitan implantar un sistema de intercambio libre de trabas. Kuran, como North o Greif (2006), entiende que la modernización económica solo es posible si el intercambio personal es sustituido por el intercambio impersonal, el cual requiere instituciones que minimicen los costos de transacción. Del análisis de la historia de Oriente Medio, no obstante, se deduce que allí no se estableció una matriz institucional que hiciera posible realizar la transición a formas de intercambio impersonal, y esa sería una causa del atraso de la región.

Mediante la comparación con instituciones de Europa Occidental durante la Edad Media, el autor identifica una serie de elementos que se opondrían a la implantación del intercambio impersonal en Oriente Medio. El sistema de herencias fue un obstáculo para la acumulación de capital y para la aparición de corporaciones mercantiles. La ley islámica otorgaba a la herencia un carácter igualitario, que no excluía a ningún pariente del difunto, lo que impedía transmitir grandes patrimonios entre generaciones. Del mismo modo, no reconocía la personalidad jurídica de la empresa, por lo que una sociedad mercantil debía disolverse si fallecía uno de sus socios, y el sistema de herencia dificultaba su reconstitución por los herederos.

Para sortear las limitaciones legales y preservar el patrimonio, la sociedad islámica recurrió a una institución de carácter religioso ya existente, el waqf, que se adaptó a la nueva finalidad, pero que a largo plazo tendría implicaciones negativas para la modernización económica. Constituir un waqf significaba convertir el patrimonio en bienes raíces, de los que disponía el administrador designado en el documento fundacional. Pero esos bienes no se podían dedicar a un fin diferente del establecido en dicho documento, que tenía vigencia perpetua, y el capital quedaba inmovilizado, sin posibilidades de emplearse en operaciones comerciales. Además, el waqf no tenía personalidad jurídica propia, por lo que tampoco podían asimilarse las ventajas de las formas jurídicas colectivas por efecto demostración.

Sin un sistema de herencia que facilitara la transmisión del patrimonio, en ausencia de corporaciones mercantiles, y con parte del capital inmovilizado en el waqf, no era factible crear formas empresariales que hicieran posibles las operaciones comerciales a gran escala y que actuaran a mediano o largo plazo; de ahí que no hubiese demanda de innovaciones organizativas similares a las que aparecían en Europa en esa misma época.

En un segundo bloque del libro, el autor profundiza el análisis de las instituciones islámicas y de sus efectos negativos sobre la moder- 
nización económica, mediante el estudio de las condiciones de las minorías no musulmanas en Oriente Medio. Progresivamente, comerciantes europeos o de minorías instaladas en los centros mercantiles de la región ganarían protagonismo en el comercio, desplazando a los comerciantes musulmanes. Esto se debió a que, como minorías religiosas protegidas ("pueblos del libro"), cristianos y judíos podían elegir bajo qué jurisdicción resolver "mejor" las disputas comerciales que les afectaban. Así, se beneficiaron de las ventajas de la legislación mercantil que se había desarrollado en Europa Occidental, y adoptaron sus formas organizativas y sus métodos de financiación.

La gran divergencia es un ejercicio ejemplar en la aplicación de una teoría económica - la nueva economía institucional- a un caso de estudio, Oriente Medio, en una visión de largo plazo y en una perspectiva comparada. Puede cuestionarse la manera de entender las instituciones de esta corriente de pensamiento, y la relevancia que concede al intercambio impersonal. Cuando apareció la versión en inglés se la criticó por equiparar Oriente Medio al Imperio Otomano, y porque parecía extrapolar las conclusiones a todo el mundo árabeislámico. Asimismo, algunos conocedores de la historia del Imperio Otomano señalaron que el estancamiento institucional narrado en el libro no encajaba bien con el hecho de que en el siglo Xvi experimentó una época de auge y expansión. A pesar de las críticas, la obra de Kuran aporta elementos para entender el estancamiento económico de una región empleando un marco que se puede aplicar para entender la evolución histórica y las posibilidades de modernización de otras sociedades.

\section{REFERENCIAS BIBLIOGRÁFICAS}

1. Greif, A. (2006). Institutions and the path to the modern economy. Cambridge: Cambridge University Press.

2. Kuran, T. (1997). Islam and underdevelopment: An old puzzle revisited, Journal of Institutional and Theoretical Economics, 153, 41-71.

3. Kuran, T. (2011). The long divergence: How Islamic law held back the Middle East. Princeton: Princeton University Press.

4. López C., F. (2016). Instituciones y subdesarrollo: a vueltas con la divergencia, Iberian Journal of the History of Economic Thought, 3(2), 106-125.

5. North, D. (1990). Institutions, institutional change and economic performance. Cambridge: Cambridge University Press.

6. North, D. y Thomas, R. (1973). The rise of the Western World. Cambridge: Cambridge University Press. 